\title{
Revizyon kalça cerrahisinde femoral sorunlar ve rekonstrüksiyon seçeneklerinin incelenmesi
}

\author{
Evaluation and classification of femoral problems and \\ reconstruction options in revision hip surgery
}

\author{
Çağatay Uluçay ${ }^{1}$, Turhan Özler ${ }^{2}$, Onur Mazmanoğlu ${ }^{1}$, Faik Altıntaş² \\ ${ }^{1}$ Dr. Çağatay Uluçay Eklem Cerrahisi ve Rehabilitasyonu Kliniği, İstanbul \\ ${ }^{2}$ Yeditepe Üniversitesi Tıp Fakültesi, Ortopedi ve Travmatoloji Ana Bilim Dalı, İstanbul
}

\begin{abstract}
Total kalça artroplastisi; kalça osteoartriti tedavisinde yüksek hasta memnuniyeti, nispeten uygulama kolaylığı ve değişik implant seçenekleri sunması nedeniyle sıklıkla uygulanan bir tedavi seçeneğidir. Buna bağlı olarak, günümüzde total kalça artroplastisi revizyonlarının sıklığı, birçok merkezde primer total kalça artroplastisi sıklığına yakın seviyelere ulaşmıştır. Bundan dolayı, bu yazıda femoral komponentin çıkarılması teknikleri ve elde kalan femura yeterli stabiliteye sahip bir femoral komponent konulması ile ilgili bilgiler verilecektir.

Anahtar sözcükler: total kalça artroplastisi; femoral komponent çıkarılması; femoral komponent revizyonu; femoral rekonstrüksiyon
\end{abstract}

\begin{abstract}
Total hip arthroplasty is a frequently applied treatment option in the treatment of hip osteoarthritis due to its high patient satisfaction, relatively ease of application, and different implant options. Therefore, the frequency of total hip arthroplasty revisions in many centers today reaches to a level almost equal to primary total hip arthroplasty operations. Therefore, this article will provide information on techniques of removing the femoral component, and implanting a new femoral component with adequate stability on the remaining femur.

Key words: total hip arthroplasty; femoral component removal; femoral component revision; femoral reconstruction
\end{abstract}

on 20 yıldır en çok yapılan ortopedi ve travmatoloji alanındaki cerrahilerden biri olan total kalça artroplastisinin (TKA) uzun sağkalımı, femoral komponentlerin kemiğe iyi tutunması sayesindedir. ${ }^{[1]}$ Ancak değişik sebeplerden dolayı revizyon ihtiyacı gelişirse, cerrahı genellikle en çok zorlayan aşama; iyi tutunmuş bir femoral komponenti, özellikle femuru kırmadan çıkarmak ve yerine yine uzun sağkalım sağlayabilecek yeni bir femoral komponent koymaktır.

\section{FEMORAL KOMPONENTIN ÇIKARTILMASI}

\section{Ameliyat Öncesi}

Femoral komponentin çıkartılması için ilk yapılması gereken, iyi görüntülemeler elde etmektir. Basit bir pelvis ve kalça anteroposterior (AP) grafisi ile revizyon ameliyatına girmek, çoğunlukla istenmeyen sonuçlar doğurur. Ülkemizde kalça osteoartritinin en sık sebebi displazi oluğu için, femoral anteversiyon genellikle yüksektir. ${ }^{[2]}$ Bununla birlikte, yaşlılarda ve
Paget hastalığında da femoral öne eğilme (bowing) artmıştır. ${ }^{[3]}$ Bunlardan dolayı, ameliyat öncesi en azından tüm femur AP ve lateral görüntülerde ölçüm yapabilecek şekilde kalibre edilmiş grafiler gereklidir. Ameliyat öncesi femurda defekt şüphesi varsa, MARS (metal artefact reduction system) sekanslı BT (bilgisayarlı tomografi) de istenebilir. Bu istenen görüntüler ile ameliyat öncesi planlama şarttır. ${ }^{[4]}$ Hatta işlerin kötü gitmesi durumunda, ameliyattan önce alternatif planlar da düşünülmelidir.

Ameliyattan önce eski ameliyatın epikrizine ve ameliyat notuna ulaşılarak, çıkarılacak implant hakkında (marka, tutulum tipi vb.) daha net bilgi sahibi olunmalıdır. Plan yapıldıktan sonra; gerekli implantlar firmadan istenmeli, eğer modüler bir stem kullanılacaksa gelen ara bağlantılar da kontrol edilmelidir. Sadece femoral komponenti değil, en kötüyü düşünerek; kablo, trokanterik kavrayıcı (grip) ve kemik çimentosu, hatta plak bile önceden sipariş edilmelidir. 


\section{Ameliyat Sırasında Uygulanabilecek Teknikler}

Cerrahi yaklaşım, eğer cerrahın kullandığı bir yaklaşım ise, çoğunlukla eski insizyon skarı üzerinden yapılır. Direkt anteriordan konmuş bir implant, eğer çok deneyiminiz yoksa, yine önden revize edilmemelidir. Bu işlem ileri derece zor olup, cerrahın femura hâkimiyetini güçleştirir. Böyle bir durumda, lateral veya posterior yaklaşım daha uygundur. ${ }^{[5]}$

Özellikle osteoporotik hastalarda, kırıkların önlenmesinde ve kapsülün temizlenmesinde minimal invaziv cerrahi yerine olabildiğince geniş yaklaşımlar daha yararlıdır. ${ }^{4]}$

Femoral osteotomiler (standart trokanterik, trokanterik kaydırma [slide], "Wagner genişletilmiş" [anterolateral] ve genişletilmiş trokanterik osteotomiler) femoral komponentin femura zarar verilmeden çıkarılmasında çok yararlıdır. Bu osteotomiler, instabiliteye veya erken gevşemeye sebep olmaz. ${ }^{[6,7]}$ Bunlardan standart trokanterik osteotomi, genellikle asetabulumun daha iyi görülmesi için yapılırken, femoral komponentin çıkartılmasında çok yarar sağlamaz. Bunun dışında, ciddi ve sık komplikasyonları dolayısıyla (abduktor yetmezlik, kaynamama, heterotrofik ossifikasyon ve implant irritasyonu) femoral revizyonlarda genellikle kullanılmaz. Trokanterik kaydırma ise, özellikle varusa deplase olmuş ve femoral komponentin omuzunun trokanter majörün içinde olduğu osteolize bağlı gevşemelerde, trokanterik kırık olmadan komponentin çıkartılmasını sağlar; komplikasyonları daha nadir olsa da standart trokanterik osteotomiye benzer. "Wagner genişletilmiş" osteotomi ise nadir kullanılan, lateral yaklaşımla abduktorları koruyan, anterolateral geniş bir osteotomidir. Özellikle, femurda aşırı anterior eğiklik olgularında komponenti çıkarmak için kullanılır. Genişletilmiş trokanterik ostetomi (extended trochanteric osteotomy -ETO) ise, artık neredeyse her tür revizyonda kullanılan ve hem femuru kırılmaktan koruyan, hem çoğunlukla cerrahi süreyi kısaltan, hem de komplikasyonları daha nadir olan bir tekniktir. Genişletilmiş trokanterik ostetomi, femoral komponentin daha kolay çıkartılması sağlamanın dışında, asetabuluma hâkimiyet, femoral deformite düzeltme, abduktor ilerletme gibi ek tedavi seçenekleri de sunar (Şekil 1). ${ }^{[1]}$

Genişletilmiş trokanterik ostetomi çimentolu femoral komponent revizyonlarında ileri gevşeme varlığında genellikle gereksiz iken; ileri derecede femoral eğriliği olan ve çimento tıkacının eğriliğin distalinde olduğu olgularda, kırılmış femoral stemlerde, tüm veya tüme yakın tutulumlu çimentosuz komponentlerde ve "double tapered" proksimal tutulumlu stemlerin çıkartılmasında altın standarttır. ${ }^{[7]}$ Ortalama $10-15 \mathrm{~cm}$ arası uzunlukta ve abduktor kolun yapışma yüzeyini

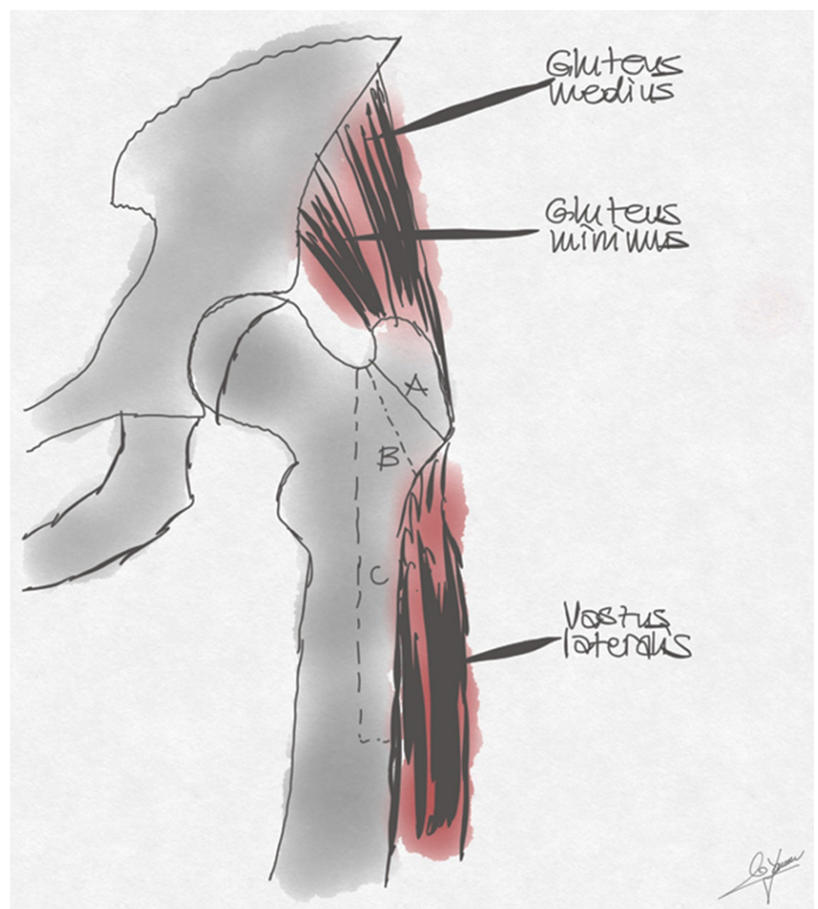

Şekil 1. Trokanterik bölge osteotomileri (A, standart trokanterik osteotomi; B, trokanterik slide osteotomi; C, genişletilmiş trokanterik ostetomi [ETO]; çizgiler osteotomi seviyelerini göstermektedir).

içine alacak şekilde femur çapının yaklaşık 1/3'ünü içeren geniş bir osteotomidir. Diğer trokanterik osteotomilere benzeyen ama daha nadir görülen komplikasyonlara sahiptir. Çimentolu stem konacak revizyonlarda, osteotomi sahasına çimento kaçağı olacağı için, ETO çok önerilmez. Komponent revizyonu sonrası kaldırılan kapak anatomik olarak redükte edilerek ortalama dört kablo ile fikse edilir (Şekil 2). ${ }^{[4]}$

Ameliyat sırasında eğer çimentolu bir komponent çıkartılacak ise; çimentonun temizlenmesi için çimento kırıcı ( $T$ veya $V$ şekilli) osteotomlar, esnek ince osteotomlar, distal tıkacı çıkarmak için uzun drill ve ters küretler, çimento parçalarını toplamak için uzun tutucular ve bunları yaparken görebilmek için soğuk ışık aparatları (en azından artroskopi ışık kaynağı) gereklidir (Şekil 3). Bunların yanı sıra, çimento kırıcı ultrasonik cihazların kullanılması da ameliyat süresini kısaltır. Femoral komponentin omzunun trokanter içine migre olduğu durumlarda dikkatli olunmalıdır. Böyle bir durumda aşırı bir güçle dışarı çekilen komponent, trokanter majör avülsiyon kırığına yol açar. Bu gibi durumlarda, ya trokanterik osteotomi yapılmalı ya da yüksek hızlı oyucu (burr) ile trokanterin içi temizlenerek komponent çıkartılmalıdır. 

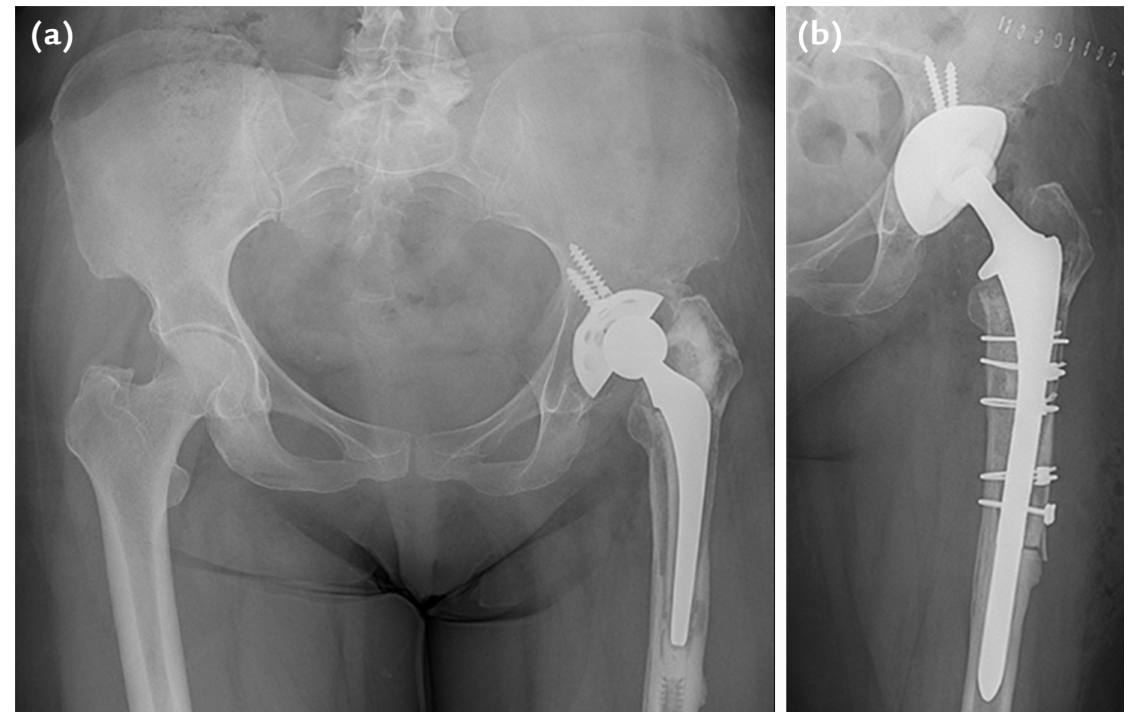

Şekil 2. a, b. Trokanter majör içine deplase olmuş femoral komponentin (a) genişletilmiş trokanterik ostetomi (ETO) ile çıkartılması (b).
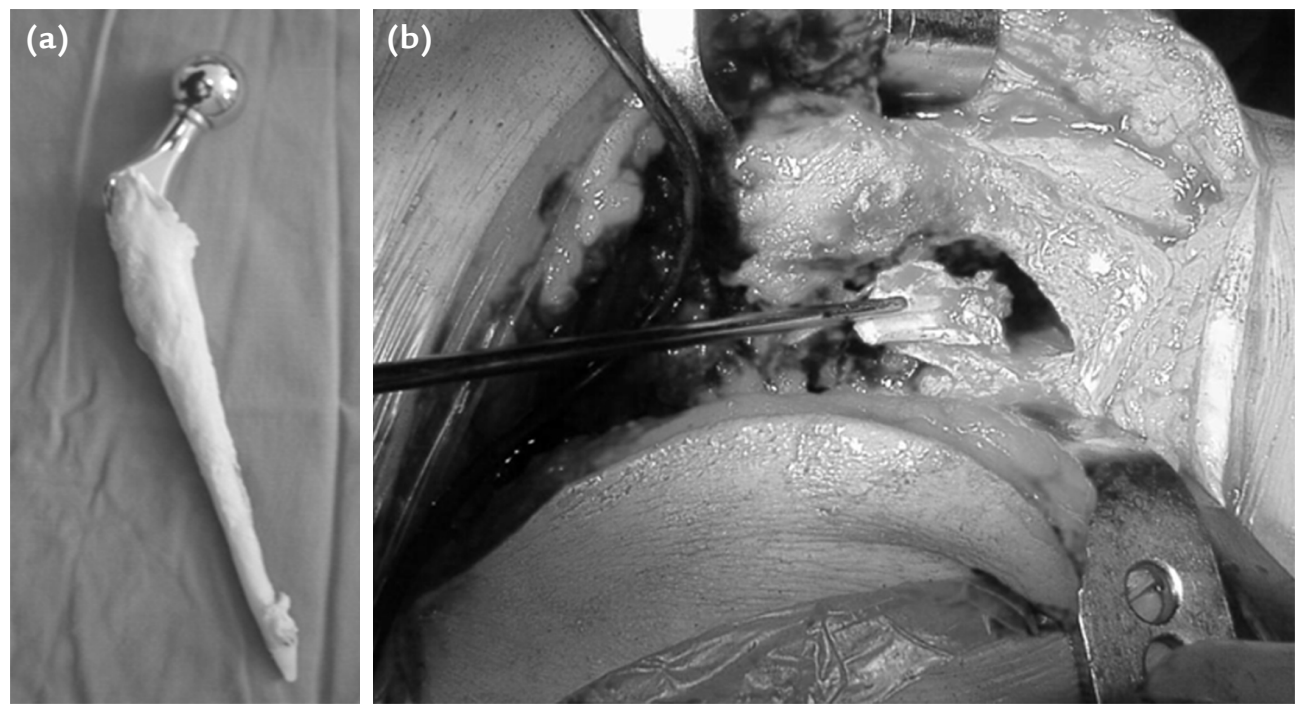

Şekil 3. a, b. Çimentonun medulladan temizlenmesi: Çimentolu femoral sitemin çıkarılmış görüntüsü (a) ve çimentonun femur medullasından temizlenmesi (b).

Eğer çimentosuz iyi tutunmuş bir komponent çıkartılacak ise, malzeme gereksinimi daha fazla olur. Genişletilmiş trokanterik ostetomide işaretleme için ince drill ve osteotomi için ince gövde kalınlığı olan testere ucu ile osteotominin uçlarını yuvarlatma amacıyla yüksek hızlı oyucu gereklidir. Komponenti femurdan gevşetirken kemik kaybını minimalize etmeyi sağlayan, çok ince gövde kalınlığı olan ve konik olmayan osteotomlar şarttır. Genişleyen osteotomlar kullanılır ise, kortekste kırık kaçınılmaz olur. Çimentosuz komponentin çıkarılması, ilk olarak üniversal çıkarıcının boyuna takılması ve 3-5 kez çok aşırı olmayan ama güçlü şekilde dışarı doğru çekme manevrasıyla başlar. Eğer komponentte herhangi bir hareket yoksa, ince düz osteotomlar ve $U$ şekilli gujlarla, proksimal bölge kemik implant ara yüzünden implanta doğru gevşetilmeye başlanır. Proksimal tutulumlu stemlerde, medial kalkar da gevşetildikten sonra, tekrar üniversal çıkarıcıya 3-5 kez vurulur. Proksimal çepeçevre gevşetilmesine rağmen yine herhangi bir hareket yoksa ve kemik osteoporotik ise, bizce ameliyat öncesi planlandığı düzeye dönülerek ETO veya Wagner osteotomisi yapılmalıdır. Bu işlem, hem ameliyat süresini kısaltacak hem de femuru kırıktan koruyacaktır. Eğer çıkartılacak 


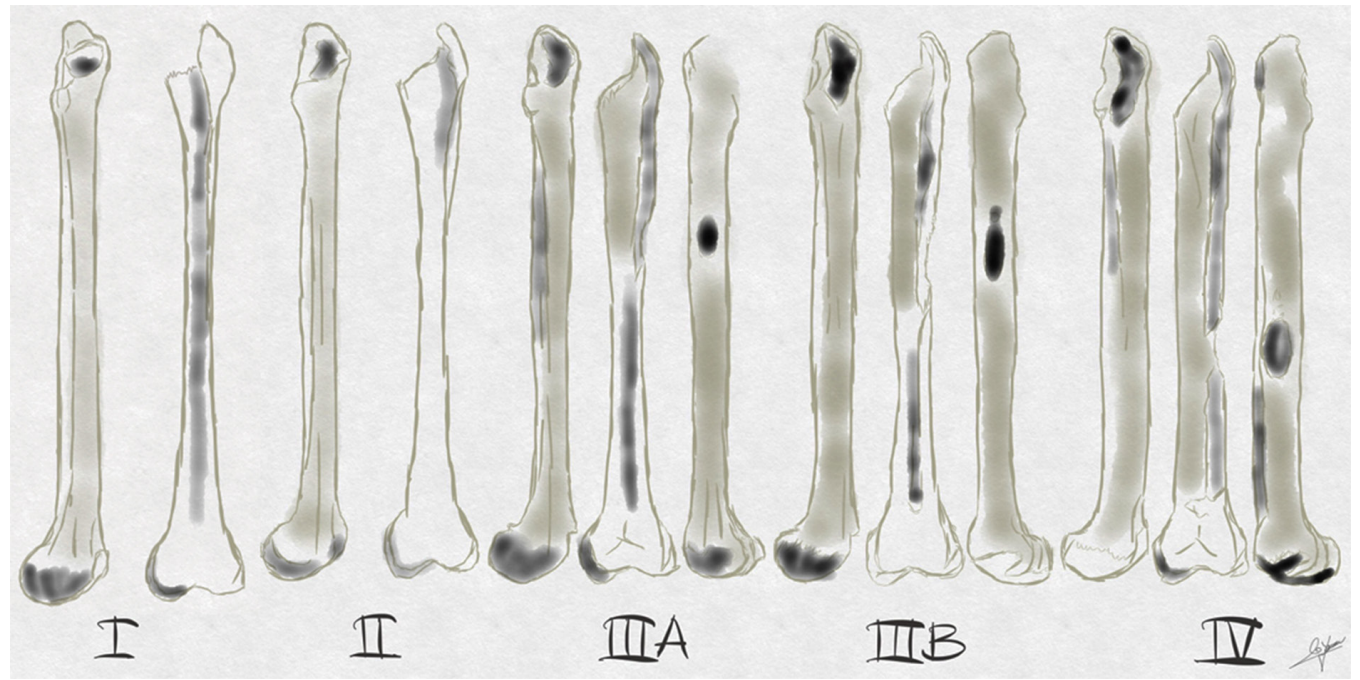

Şekil 4. Paprosky femoral kemik kaybı sınıflaması.

stem tüm veya tüme yakın yüzey tutulumlu uzun silindirik bir komponent (Echelon ${ }^{\circledR}$ Smith and Nephews, $\mathrm{AML}^{\circledR}$, Prodigy DePuy ${ }^{\circledR}$ vb.) ise direkt ETO ile ameliyat başlanması önerilir. Ameliyat öncesi planlamaya göre istmusta 4-6 cm'lik sağlam kemik doku kalacak kadar osteotomi distale uzatılır. Eğer çıkacak komponent bu seviyeden daha distale devam ediyor ise iki ayrı seçeneğiniz vardır. Ya en uca dek osteotomiyi devam ettirir ve modüler veya özel yapım bir femoral komponent ile revize edersiniz (istmustaki 4-6 cm'lik minimal tespit yüzeyini kaybedeceğiniz için, monoblok distal tutulumlu bir komponent koyamazsınız) ya da ilk silindirik gövdeye sahip olduğu yere kadar femoral osteotomi yapıp, ulaştığınız stemi metal kesicilerle keser ve içerde kalan stemin distalini trefinle (Trephine ${ }^{\circledR}$ DePuy) çıkarırsınız. Trefin, yüksek hızlı oyucu ve metal kesici kullanırken, kemiğin suyla soğutulmasına önem verilmesi gereklidir. Ĕger soğutma uygulanmazsa, kemikte termal hasar gelişecek ve bu hasar konan revizyon komponentin osteointegrasyonunu bozacaktır. ${ }^{[4]}$

Geçmişte ameliyat sonrası takip metotları, ETO sonrası kalça abduksiyon cihazı kullanımı, 12 haftaya dek basmanın kısıtlanması ve kalça hareketlerini altı hafta engellenmesi şeklindeydi. Günümüzde ameliyat sonrası takip; cerrahın yaklaşımına, kemik kalitesine ve osteotomi tespitinin stabilitesine bağlı olarak, çoğunlukla rutin revizyon ameliyatından farksız şekilde planlanır.

\section{FEMORAL KEMIK KAYBININ SINIFLANDIRILMASI}

Femoral revizyonlarda kemik kaybını sınıflandırılması için birçok ayrı sınıflandırma olsa da (AAOS
- American Academy of Orthopaedic Surgeons, EndoKlinik, Mallory, Saleh, Enhg-Glassman vb. ${ }^{[1]}$, yazarlar daha sık kullanılan, öğrenmesi daha basit ve sınıflandırma-tedavi seçeneği ilişkisi olan Paprosky sınıflamasını anlatacaktır. ${ }^{\left[{ }^{[8]}\right.}$ Sınıflandırmanın temeli metafiz ve/veya diyafizdeki defektin büyüklüğü ve kalan kemiğin kalitesi üzerine kuruludur (Şekil 4).

Tip 1: Spongiyöz kemik kaybı sadece metafiziyel olup, proksimal femurda remodelling yoktur.

Tip 2: Metafizde ciddi spongiyöz kemik kaybı varken, diyafizde ve kortekste kayıp yoktur ama proksimal femurda remodelling vardır.

Tip 3: Metafiz ve diyafizde ciddi spongiyöz kemik kaybı ve proksimal femurda ciddi remodelling vardır. Burada diyafizde (istmus) en az $4 \mathrm{~cm}$ sağlam kortikal yüzeyin bulunup bulunmamasına göre ikiye ayrılır. Bu $4 \mathrm{~cm}$ kuralı aslında diyafız medullasının ölçümünün iki katıdır. Tedavi seçenekleri bölümünde bu ayrımın gerekçesi daha net açıklanacaktır.

Tip 3A: Femur metafizi ciddi şekilde hasarlı olup, metafiziyel tutulumlu bir komponente yeterli destek sağlamayacaktır. Ama diyafiz bölgesinde en az $4 \mathrm{~cm}$ 'lik sağlam bir segment vardır.

Tip 3B: Femur metafizi ciddi şekilde hasarlı olup, metafiziyel tutulumlu bir komponente yeterli destek sağlamayacaktır. Bununla birlikte, diyafiz bölgesinde $4 \mathrm{~cm}$ 'den daha kısa sağlam bir segment vardır.

Tip 4: Hem proksimal metafiz hem de diyafizde ciddi kemik (spongiyöz ve kortikal) kaybı ve femoral kanalda ciddi bir genişleme vardır. 

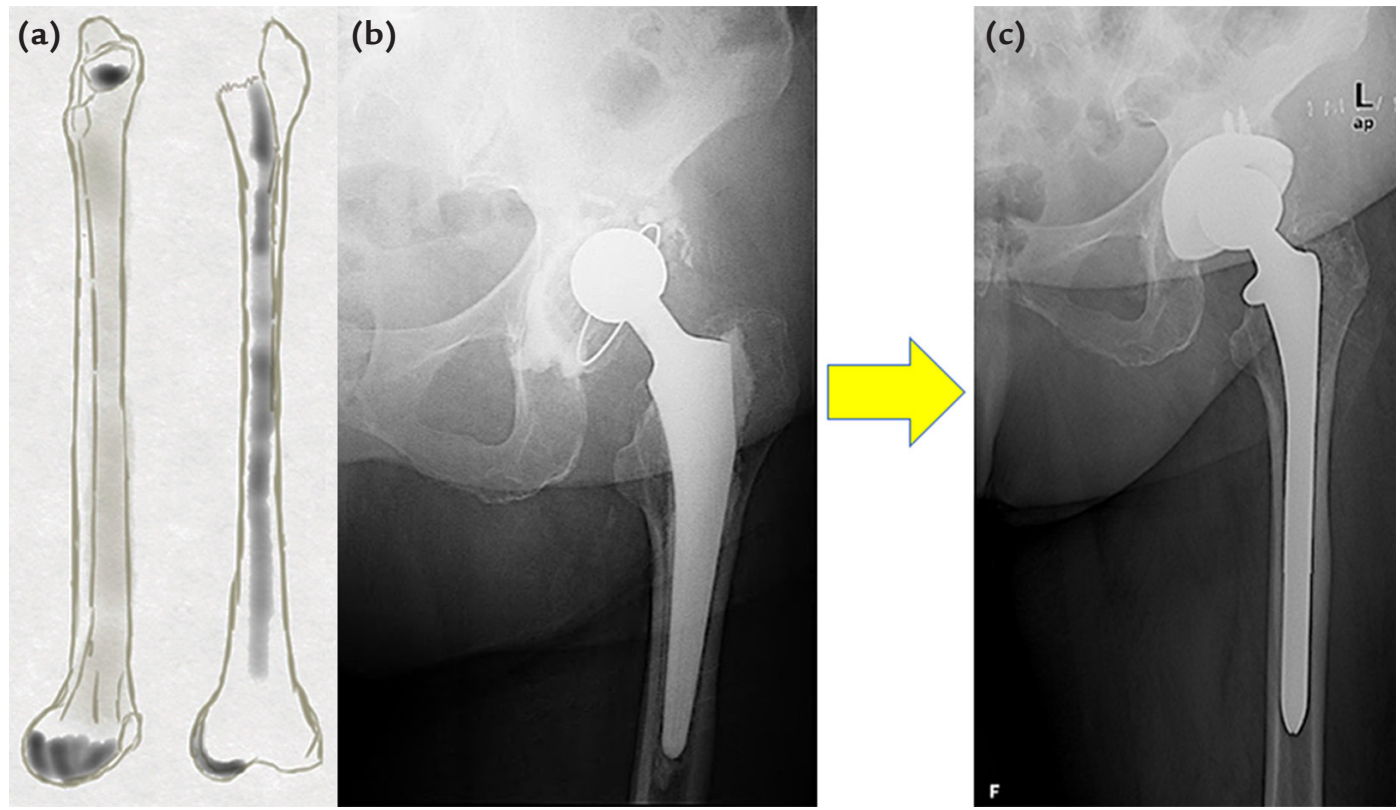

Şekil 5. a-c. Tip 1 bir femurun (a ve b) tüme yakın poröz kaplı silindirik bir femoral komponent ile revizyonu (c).

\section{FEMORAL KEMIK KAYBINA BAĞLI OLARAK REKONSTRÜKSIYON SEÇENEKLERi}

Bu bölümde Paprosky sınıflamasındaki tiplere göre önerilen femoral komponent seçenekleri anlatılacaktır.

Tip 1: Ciddi bir kemik kaybı olmadığı için, primer femoral komponent uygulamasından pek farkı yoktur. Bazı seçilmiş olgularda proksimal tutulumlu primer bir femoral komponent ile revizyon bile mümkündür. Ancak genel olarak, silindirik tüm veya tüme yakın poröz kaplı bir femoral komponent ile revizyon yapılır. Özellikle enfeksiyon hikâyesi olan olgularda antibiyotikli çimento kullanılarak yapılan çimentolu femoral revizyon da seçenekler içindedir. ${ }^{[9]}$ TKA revizyonlarında en başarılı sonuç bu tipte yapılan revizyonlarda olup, genellikle femoral sağkalım primer komponent sağkalımı ile benzerdir (Şekil 5). ${ }^{[10,11]}$

Tip 2: En sık karşılaşılan tiptir. Proksimal femur metafizinde ciddi spongiyöz kemik kaybı ve proksimal femurda remodelling varken, diyafizde ve kortekste kayıp yoktur. Bu tipin revizyonunda, komponentin çıkarılması için çoğunlukla ETO tarzı bir osteotomi gerekeceğinden, çimentolu femoral komponentten uzak durulmalıdır. ${ }^{[12]} \mathrm{Bu}$ aşamada artık primer femoral komponentler kullanılamaz. Silindirik, tüm veya tüme yakın poröz kapI diyafizer tutulumlu monoblok bir femoral komponent (Echelon ${ }^{\circledR}$ Smith and Nephews, $\mathrm{AML}^{\circledR}$, Prodigy ${ }^{\circledR}$ DePuy, Wagner $\mathrm{SL}^{\circledR}$, $\operatorname{Arcos}^{\circledR}$ Zimmer vb.) veya modüler bir femoral komponent (S-ROM modular ${ }^{\circledR}$ DePuy, Arcos modular ${ }^{\circledR}$ Zimmer) ile çimentosuz revizyon uygulanır. Sonuçlar, iyi primer stabiliteye uyulduğu takdirde, komponent tipinden bağımsız ve tip 1 gibi çok başarılıdır (Şekil 6). ${ }^{[13]}$

Tip 3: Metafiz ve diyafizde ciddi kayıp ve ciddi proksimal femurda remodelling vardır. Bu aşamada da herhangi bir primer femoral komponentin stabil olarak tutunma ihtimali yoktur. Burada, diyafizde (femur istmusunda) en az $4 \mathrm{~cm}$ sağlam yüzeyin bulunup bulunmamasına göre bu tip ikiye ayrılır. Bu ayrımın temeli, kullanılacak olan femoral komponentin seçimi ve sağkalımlar arasındaki farktır. ${ }^{[13,14]}$ Distal tutulumlu monoblok tama yakın poröz silindirik bir revizyon ve femoral komponentin stabil fiksayonu için, istmusta minimum o seviyedeki iki medulla çapı kadar (ortalama 4-6 cm) sağlam bir kortikal devamlılık gerekir. Eğer böyle bir devamlılık yoksa veya 19 mm'den daha geniş medulla çapı varsa, monoblok poröz distal tutulumlu komponentler yeterli primer stabiliteye sahip olamaz ve başarısızlık kaçınılmaz olur. Bundan dolayı, bu tarz femurlarda modüler ve özellikle yivli (fluted) daralan (tapered) femoral komponent ile revizyon gereklidir. 


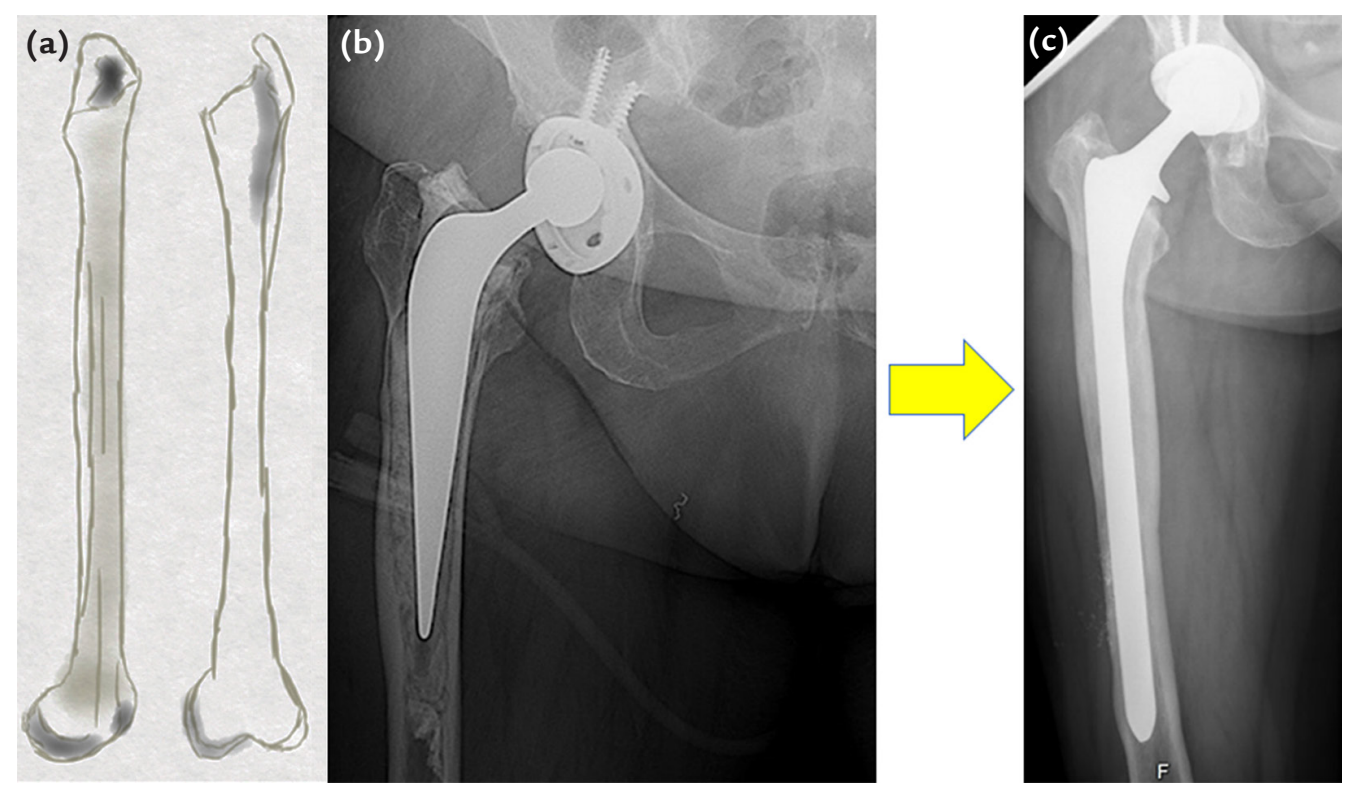

Şekil 6. a-c. Tip 2 bir femurun (a ve b) tüme yakın poröz kaplı silindirik bir femoral komponent ile revizyonu (c).

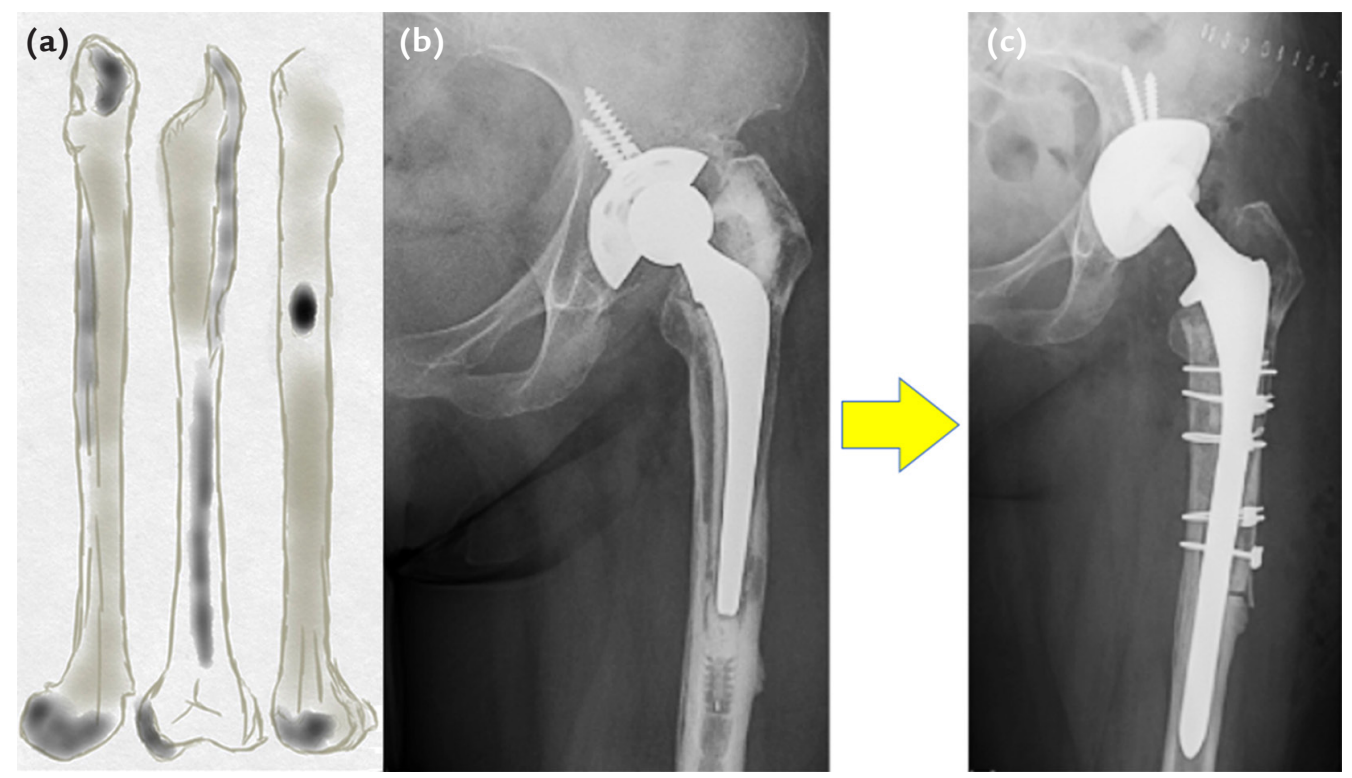

Şekil 7. a-c. Tip 3A bir femurun (a ve b) ETO sonrası tüme yakın poröz kaplı silindirik bir femoral komponent ile revizyonu (c).

Tip 3A: Femur metafizi ciddi şekilde hasarlı olup, metafiziyel tutulumlu bir komponente yeterli destek sağlamayacaktır ama diyafiz bölgesinde en az $4 \mathrm{~cm}$ 'lik sağlam bir segment vardır. Bu tarz revizyonlarda çoğunlukla, implantın çıkarılması için ETO gerekebilir. Medulla hazırlandıktan sonra istmustaki sağlam bölüm ölçülür ve en az $4 \mathrm{~cm}$ uzunluk var ve medulla çapı 19 mm'den dar ise, genellikle silindirik tüm veya tüme yakın poröz kaplı diyafizer tutulumlu monoblok bir femoral komponent (Echelon ${ }^{\circledR}$ Smith and Nephews, $\mathrm{AML}^{\circledR}$, Prodigy ${ }^{\circledR}$ DePuy, Wagner $\mathrm{SL}^{\circledR}, \operatorname{Arcos}^{\circledR}$ Zimmer vb.) ile stabilite sağlanır. Seçilmiş olgularda var olan kortikal defektlere ileride yapılacak bir revizyonda kemik stoğu sağlamak için kortikal greftler ile destek sağlanabilir. Uzun dönem sağkalım \%94 ve üzerindedir (Şekil 7). ${ }^{[1]}$ 


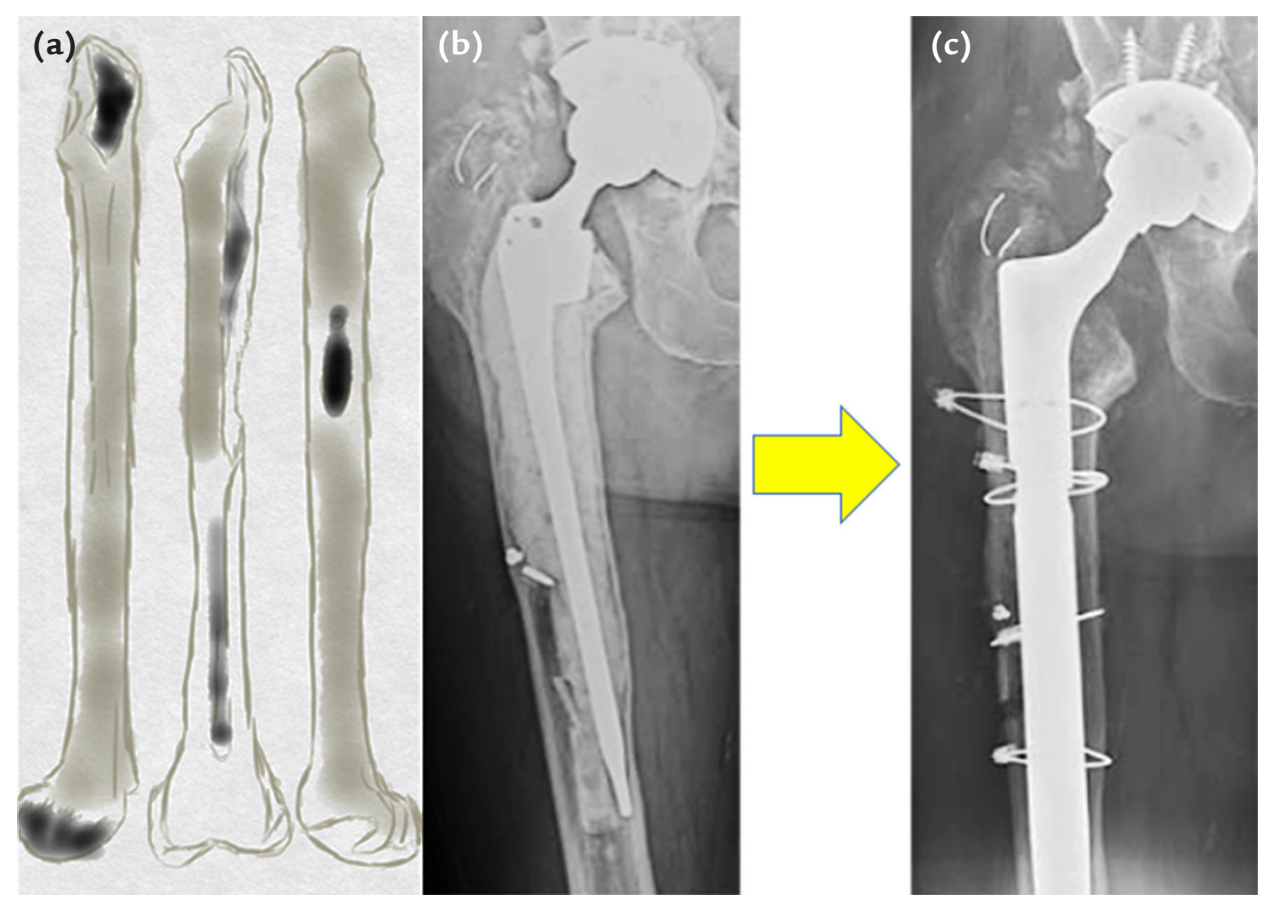

Şekil 8. a-c. Tip 3B bir femurun (a ve b) ETO modüler çimentosuz femoral komponent ile revizyonu (c).

Tip 3B: Femur metafizi ciddi şekilde hasarlı olup, metafiziyel tutulumlu bir komponente yeterli destek sağlamayacaktır. Bununla birlikte, diyafiz bölgesinde de $4 \mathrm{~cm}$ 'den daha kısa sağlam bir segment vardır. Böyle bir durumda monoblok bir femoral komponent kullanılamaz. Bu tarz olgularda çimentosuz modüler bir femoral komponent (S-ROM modular $^{\circledR}$ DePuy, Arcos modular ${ }^{\circledR}$ Zimmer) $^{2}$ dışında yeterli primer stabilizasyon sağlanamaz. Günümüzde kullanılan yeni nesil yivli (fluted) daralan (tapered) modüler çimentosuz femoral komponentler ile, yaklaşık 2 $\mathrm{cm}$ 'lik bir diyafizer tutulum ve yeterli primer stabilizasyon sağlanır. ${ }^{[4]}$ Modüler femoral komponent kullanımı; göreceli olarak kolay uygulanabilir olmasına, her tür gereksinime ve versiyona izin verebilmesine rağmen, eskiden daha sık olsa da günümüzde de hâlâ bağlantı yerlerinde kırılma görülebilmektedir. ${ }^{[13,15]}$ Ayrıca bunlar, monoblok stemlere göre anlamlı düzeyde pahalıdır (Şekil 8). Tip 3B ve 4 femoral revizyonda, çimentosuz komponentler dışında çimentolu komponentlerle de kullanılabilir. Bu yöntem, eski yıllarda sıklıkla, ancak günümüzde nadir olarak kullanılmaktadır. Korteksteki defektler ya titanyum meshler ya da kortikal greftler ile kapatılır ve "impaction bone grafting" tekniği ile medulla hazırlanır. ${ }^{[12,16-18]}$ Tekniğe uygun şekilde hazırlanan medullanın içine çimentolu bir femoral komponent konulur. Orta dönem sağkalım sonuçları \%95 civarındadır. ${ }^{[17,18]}$ Başarılı sonuçlarının yanı sıra, bu teknik ile ameliyattan sonra da gerekebilecek revizyonlar için yeterli kemik stoğu oluşturulur. Ancak bu teknik, hem uygulaması zor, hem ameliyat süresini ortalama 1-2 saat uzatan, hem de ciddi miktarda özellikle taze spongiyöz allogreft ihtiyacı gösteren, üstelik kortikal defektler için kortikal allogreft veya mesh gerektiren çok pahalı bir tekniktir. Bundan dolayı, günümüzde sadece seçilmiş olgularda kullanılmaktadır.

Tip 4: Hem proksimal metafiz hem de diyafizde ciddi kemik (spongiyöz ve kortikal) kaybı ve femoral kanalda ciddi bir genişleme vardır. İstmusta distal tespit için yeterli sağlam bölge kalmamıştır. Medulla 19 mm'den geniş olup, mevcut hiçbir poröz stem ile yeterli tespit sağlanamaz. Böyle bir durumda, femur rekonstrüksiyonu ve replasmanı arasında seçim yapılması gereklidir. Biyolojik rekonstrüksiyon 


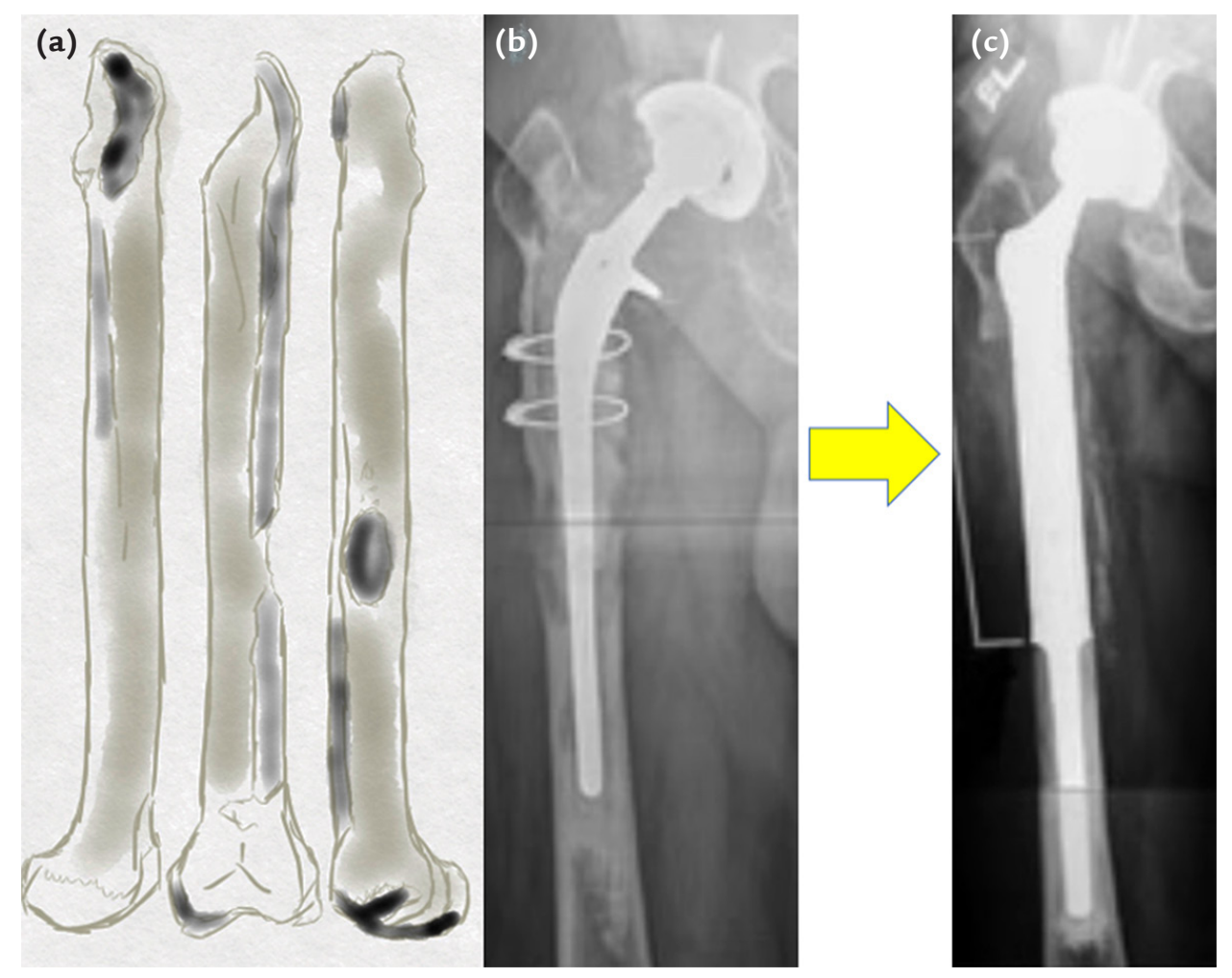

Şekil 9. a-c. Tip 4 bir femurun (a ve b) proksimal femoral replasmanı ile revizyonu (c).

için "impaction bone grafting”, taze proksimal femur allogrefti ile rekonstrüksiyon, çoklu kortikal allogreft ile femur rekonstrüksiyonu sonrası çimentosuz yivli (fluted) daralan (tapered) modüler femoral komponent seçeneklerinden biri kullanılır (Şekil 9). ${ }^{[19]}$

Bunların her birinin kendine has zorlukları ve avantajları vardır. Günümüzde, bu kadar zor revizyonlarda ve özellikle ileri yaştaki hastalarda, proksimal femur replasmanı daha sık uygulanmaktadır; pahalı olmasına rağmen, kısa dönemde yüksek sağkalım ve düşük tekrarlayan operasyon riski taşır. ${ }^{[20]}$ Ancak unutulmamalıdır ki, özellikle genç hastalarda bu ameliyat sonrası yeniden revizyon gerekince, muhtemelen elinizde bütün (pan) femur protezi dışında hiçbir tedavi seçeneği kalmayacaktır. Bundan dolayı, ameliyatı kolay ve kısa olsa da, özellikle genç hastalarda bu implantı kullanmanız önerilmez.

\section{SONUÇ}

Femoral komponentin revizyonu, TKA revizyonunda önemli bir yer tutar. Femoral komponent çıkarıldığında elde kalan kemik stoğu, yapılacak revizyonun sağkalım süresi ile direkt ilişkilidir. Bunun için; dikkatli bir ameliyat öncesi planlama, strateji belirleme, ameliyat içinde konsantre ve sabırlı şekilde çalışma şarttır. Elde kalan femuru mümkün olduğunca biyolojiye saygılı şekilde rekonstrükte edersek, hem implantın sağkalımını uzatır hem de hastanın bundan sonraki revizyonlarda kullanılabilecek sağlam kemik dokusuna sahip olabiliriz.

\section{Teşekkür ve Katkı}

Makale içerisindeki tıbbi şekil çizimlerindeki katkılarından dolayı Ufuk Üniversitesi Tıp Fakültesi, Ortopedi ve Travmatoloji Ana Bilim Dalı Araş. Gör. Dr. Alperen Kaan Yaman'a sonsuz teşekkürlerimi iletiyorum.

\section{KAYNAKLAR}

1. Lieberman JR, Berry DJ, editors. Advanced Reconstruction: Hip 2. The Hip Society (AAOS - American Academy of Orthopaedic Surgeons); 2018.

2. Uluçay C, Ozler T, Güven M, Akman B, Kocadal AO, Altıntaş F. Etiology of coxarthrosis in patients with total hip replacement. Acta Orthop Traumatol Turc 2013;47(5):330-3. Crossref

3. Shimosawa $H$, Nagura $T$, Harato K, Kobayashi S, Nakamura M, Matsumoto M, Niki Y. Variation of three-dimensional femoral bowing and its relation to physical status and bone mineral density: a study with CT. Surg Radiol Anat 2019;41(12):1489-95. Crossref 
4. Berry DJ, Lieberman JR. Surgery of the Hip, 2nd ed. Philadelphia: Elsevier; 2020.

5. Hasler J, Flury A, Dimitriou D, Finsterwald M, Helmy N, Antoniadis $A$. Is revision total hip arthroplasty through the direct anterior approach feasible? Arch Orthop Trauma Surg 2020;140(8):1125-32. Crossref

6. Tarity TD, Xiang W, Gkiatas I, Meyers KN, Malahias M-A, Rodriguez JA, Wright TM, Sculco PK. Extended Trochanteric Osteotomy Closure Performed Before or After Canal Preparation and Stem Impaction Does Not Affect Axial Stability. J Arthroplasty 2021;S0883-5403(21)00629-X. Crossref

7. Garabano G, Gessara AM, Pesciallo CA, Alamino LP, del Sel H. Extended trochanteric osteotomy (ETO) and fluted tapered modular stems in revision hip arthroplasty. Does ETO integrity or consolidation, really matter? J Orthop 2021;23:250-5. Crossref

8. Della Valle CJ, Paprosky WG. Classification and an algorithmic approach to the reconstruction of femoral deficiency in revision total hip arthroplasty. J Bone Joint Surg Am 2003;85A Suppl 4:1-6. Crossref

9. Gandhi R, Backstein D, Zywiel MG. Antibiotic-laden Bone Cement in Primary and Revision Hip and Knee Arthroplasty. J Am Acad Orthop Surg 2018;26(20):727-34. Crossref

10. Skibicki HE, Post ZD, Kay AB, Czymek MM, Ong AC, Orozco FR, Ponzio DY. A Role for Modern Primary Cementless Femoral Stems in Revision Hip Arthroplasty. J Arthroplasty 2021;36(9):3269-74. Crossref

11. Salduz A, Kılıçoğlu Öi, Ekinci M, Yıldız E, Tözün R, Yazıcıoğlu Ö. Midterm results of the cylindrical fully porouscoated uncemented femoral stem in revision patients with Paprosky I-IIIA femoral defects. J Orthop Surg (Hong Kong) 2018;26(2):2309499018783906. Crossref

12. Petrie MJ, Harrison TP, Buckley SC, Gordon A, Kerry RM, Hamer AJ. Stay Short or Go Long? Can a Standard Cemented Femoral Prosthesis Be Used at Second-Stage Total Hip Arthroplasty Revision for Infection Following an Extended Trochanteric Osteotomy? J Arthroplasty 2017;32(7):2226-30. Crossref
13. Yacovelli S, Ottaway J, Banerjee S, Courtney PM. Modern Revision Femoral Stem Designs Have No Difference in Rates of Subsidence. J Arthroplasty 2021;36(1):268-73. Crossref

14. Moriarty P, Sheridan GA, Wong L, Guerin S, Gul R, Harty JA. Bicortical Contact Predicts Subsidence of Modular Tapered Stems in Revision Total Hip Arthroplasty. J Arthroplasty 2020;35(8):2195-9. Crossref

15. Sukopp M, Taylor D, Forst R, Seehaus F. Femoral Stem Fracture in Hip Revision Arthroplasty: A Systematic Literature Review of the Real-World Evidence. Z Orthop Unfall 2021. [Online ahead of print]. Crossref

16. Verspeek J, Nijenhuis TA, Kuijpers MFL, Rijnen WHC, Schreurs BW. What Are the Long-term Results of Cemented Revision THA with Use of Both Acetabular and Femoral Impaction Bone Grafting in Patients Younger Than 55 Years? Clin Orthop Relat Res 2021;479(1):84-91. Crossref

17. Stigbrand H, Ullmark G. A 3- to 18-Year Follow-Up of Revision Total Hip Arthroplasty With Impacted Bone Allografts and Cemented Lubinus SP II Stem. Clinical, Radiographic, and Survivorship Analysis With Comparison to the Literature. J Arthroplasty 2017;32(9):2810-4. Crossref

18. Fadulelmola A, Drampalos E, Hodgkinson J, Hemmady M. Survivorship Analysis of Eighty Revised Hip Arthroplasties With the Impaction Grafting Technique Using Whole Femoral Head Allografts With the Articular Cartilage. J Arthroplasty 2017;32(6):1970-5. Crossref

19. Otero JE, Martin JR, Rowe TM, Odum SM, Mason JB. Radiographic and Clinical Outcomes of Modular Tapered Fluted Stems for Femoral Revision for Paprosky III and IV Femoral Defects or Vancouver B2 and B3 Femoral Fractures. J Arthroplasty 2020;35(4):1069-73. Crossref

20. De Martino I, D'Apolito R, Nocon AA, Sculco TP, Sculco PK, Bostrom MP. Proximal femoral replacement in nononcologic patients undergoing revision total hip arthroplasty. Int Orthop 2019;43(10):2227-33. Crossref 